\title{
Virus-Specific Antibody, in the Absence of T Cells, Mediates Demyelination in Mice Infected with a Neurotropic Coronavirus
}

\author{
Taeg S. Kim and Stanley Perlman*† \\ From the Interdisciplinary Program in Immunology* and the \\ Departments of Pediatrics and Microbiology, ${ }^{\dagger}$ University of Iowa, \\ Iowa City, Iowa
}

\begin{abstract}
Mice infected with mouse hepatitis virus strain JHM develop an inflammatory demyelinating disease in the central nervous system with many similarities to human multiple sclerosis. The mouse disease is primarily immune-mediated because demyelination is not detected in JHM-infected mice lacking $T$ or B cells but does occur after transfer of JHM-specific T cells. Although less is known about the ability of antibodies to mediate demyelination, the presence of oligoclonally expanded B cells and high concentrations of antibodies (against self or infectious agents) in the central nervous system of many multiple sclerosis patients suggests that antibodies may also contribute to myelin destruction. Here, we show that anti-JHM antibodies, in the absence of $T$ or $B$ cells, caused demyelination in JHM-infected mice. Anti-JHM antibody was detected adjacent to areas of demyelination, consistent with a direct interaction between antibody and infected cells. Demyelination was reduced by 85 to $90 \%$ in infected $\mathrm{RAG1}^{-/-}$mice lacking normal expression of activating $\mathrm{Fc}$ receptors $\left(\mathrm{FcR} \gamma^{-/-}\right)$and by $\sim \mathbf{7 6} \%$ when complement was depleted by treatment with cobra venom factor. These data demonstrate that JHM-specific antibodies are sufficient to cause demyelination and that myelin destruction in the presence of anti-virus antibodies results from a combination of complement- and Fc receptor-dependent mechanisms. (Am J Patbol 2005, 166:801-809)
\end{abstract}

The human disease multiple sclerosis (MS) is an immunemediated, chronic inflammatory disease manifested clinically by neurological deficits and histologically by multiple foci of demyelination. T cells are detected in active demyelinating lesions and a critical role for these cells in demyelination has been clearly demonstrated in several animal models of demyelination, including rodents with experimental autoimmune encephalitis (EAE) and mice infected with coronaviruses or Theiler's murine encephalomyelitis virus. ${ }^{1-3}$

Mice infected with the neurotropic JHM strain of mouse hepatitis virus (JHM) develop acute and chronic demyelinating diseases. We and others ${ }^{4-6}$ have shown that demyelination was not detected in JHM-infected mice lacking $T$ and $B$ cells [either mice with severe combined immunodeficiency or mice lacking functional recombination activating enzyme $1\left(\mathrm{RAG}^{-1-}{ }^{-1}\right)$. However, adoptive transfer of syngeneic splenocytes from JHM-immune mice resulted in rapid and reproducible demyelination. ${ }^{6,7}$ Depletion of $\mathrm{T}$ cells abrogated demyelination showing that $T$ cells were necessary and $B$ or other splenic cells were not sufficient for demyelination to occur. Either CD8 or CD4 T cells, in the absence of the other subset, were able to mediate demyelination in this model. ${ }^{4}$ In these experiments, T cells were transferred into RAG $1^{-\prime-}$ mice 4 days after they were immunized with JHM. The innate immune system was activated by JHM infection before Tcell transfer, as shown by up-regulated expression of several proinflammatory cytokines and chemokines, such as tumor necrosis factor- $\alpha$, MIP-2, CCL7 (MCP-3), CCL4 (MIP$1 \beta$ ), CCL2 (MCP-1), CXCR10 (IP-10), and CCL5 (RANTES) in the central nervous system (CNS). ${ }^{8}$ This intense inflammatory milieu is likely critical for the rapid recruitment and activation of $\mathrm{T}$ cells to the CNS after adoptive transfer.

Less is known about the role of humoral immune factors in MS, but several features suggest that B cells or antibodies are involved in myelin destruction. ${ }^{9}$ Oligoclonal expansion of $\mathrm{B}$ cells is observed in the cerebrospinal fluid of patients with MS. Also, high levels of immunoglobulin are detected in the cerebrospinal fluid. ${ }^{10}$ Some of these cerebrospinal fluid-derived antibodies are directed against myelin proteins and pathogens such as Epstein-Barr virus ${ }^{11}$ and varicella-zoster virus. ${ }^{12}$ In addi-

Supported in part by grants from the National Institutes of Health (R01 NS 40438) and the National Multiple Sclerosis Society (RG 2864-B-3).

Accepted for publication November 15, 2004.

Address reprint requests to Dr. Stanley Perlman, Department of Pediatrics, University of lowa, Medical Laboratories 2042, Iowa City, IA 52242 E-mail: stanley-perlman@uiowa.edu. 
tion, circulating antibodies against myelin proteins are detected in patients with $\mathrm{MS}^{13,14}$ and are a marker for the subsequent development of MS in patients with single episodes of a first neurological event. ${ }^{15}$ Furthermore, depositions of IgG and complement have been detected at sites of active demyelination in these patients. ${ }^{16} \mathrm{Mul}-$ tiple studies using rodent models of EAE also indicate that antibodies may have an important role in the demyelinating process. In mice, rats, and marmosets, treatment with antibody directed against an epitope of myelin oligodendrocyte glycoprotein resulted in the rapid onset of demyelination. ${ }^{17}$ Antibody was detected at sites of myelin destruction. ${ }^{13,18}$ The mechanism of antibody-mediated demyelination is not known with certainty. Several studies showed that complement depletion with cobra venom factor (CVF) resulted in delayed onset of EAE and a reduction in demyelination. ${ }^{19}$ EAE has been reported to be ameliorated ${ }^{20}$ or unaffected ${ }^{21}$ in mice deficient in C3 expression. Other studies implicate a role for the terminal components of complement in demyelination, via formation of membrane attack complex (MAC). ${ }^{22,23}$ MAC has multiple functions, including direct cell lysis and enhancement of phagocytosis. Fc receptors (FcR) that are involved in the interaction of antibodies with effector cells, including macrophages, have also been implicated in antibody-induced demyelination. ${ }^{24}$ Mice deficient in expression of activating FCR (Fc $\gamma R \mathrm{RI}$ and $\mathrm{Fc}_{\mathrm{C}} \gamma \mathrm{RIII}$ ) develop less disease and demyelination whereas disease is exacerbated in mice lacking expression of the inhibitory Fc $\gamma$ RII molecule.

These studies suggest that antibody directed against a CNS antigen can mediate demyelination and that this process involves both signaling through the FCR and complement activation. However, these studies were always performed in animals with intact $\mathrm{T}$ - and B-cell compartments, making it difficult to determine the precise role of antibody in the demyelinating process. For example, $\mathrm{C} 3 \mathrm{a}$ and $\mathrm{C5a}$ both increase expression of adhesion molecules and can serve as chemoattractants for macrophages and $\mathrm{T}$ cells. ${ }^{25} \mathrm{C} 5 \mathrm{a}$ is also required for optimal T-cell activation because treatment of mice with a $\mathrm{C5a}$ antagonist results in a diminished CD8 T-cell response. ${ }^{26}$ Therefore, administration of anti-myelin oligodendrocyte glycoprotein antibody may initiate the demyelinating process, but demyelination may be primarily $T$ cell-mediated, with complement activation serving to enhance the T-cell response.

Our previous results showed that an inflammatory state existed in the CNS of JHM-infected $\mathrm{RAG}^{-1-}$ mice but that demyelination was not detected in the absence of transferred $\mathrm{T}$ cells. As a consequence, this model is excellent for determining whether transfer of anti-virus antibody, in the absence of any transferred T or B cells, is sufficient to mediate demyelination.

\section{Materials and Methods}

\section{Animals}

Pathogen-free C57BL/6 (B6) mice were purchased from the National Cancer Institute (Bethesda, MD). Specific pathogen-free $\mathrm{RAG}^{-1-}$ mice were purchased from Jackson Laboratories (Bar Harbor, ME) and bred at the University of lowa (lowa City, IA). FCR $\gamma^{-/-}$mice (B6x129; a generous gift from Dr. Timothy Ratliff, University of lowa) were bred with $\mathrm{RAG}_{1}{ }^{-1-}$ mice to generate $\mathrm{FCR} \gamma^{-1-}$ RAG1 ${ }^{-1-}$ mice. As a control group for experiments using $\mathrm{FCR} \gamma^{-1-} \mathrm{RAG}^{-/-}$mice, age-matched littermates that were heterozygous for the $\mathrm{FCR} \gamma^{-1-}$ were used $\left(\mathrm{FCR} \gamma^{+/-}\right.$ $\left.\mathrm{RAG}^{-1-}\right)$. Six- to eight-week-old animals were used for all studies. All animal studies were approved by the University of lowa Animal Care and Use Committee.

\section{Induction of Demyelination}

$\mathrm{RAG}^{-1-}$ mice were inoculated intracerebrally with 1000 plaque forming units (PFU) of the attenuated J2.2-V-1 strain of JHM (a generous gift from Dr. J. Fleming, University of Wisconsin, Madison, WI) in $30 \mu$ l of Dulbecco's modified Eagle's medium. Four days later, antibody was delivered intraperitoneally in $500 \mu$ l of sterile phosphatebuffered saline (PBS). Rabbit polyclonal anti-JHM antibody was prepared as described previously. ${ }^{27}$ The neutralizing titer (NT) of this antibody was 1:1862 plaque reduction units $(\mathrm{PRD}) / \mathrm{ml}$. Monoclonal antibodies (mAbs) used in these experiments include: 5B19.2 [anti-surface (S) glycoprotein; IgG1, NT: 1:2410 PRD/mg], 5A13.5 (anti-S; IgG2a, NT: 1:6230 PRD/mg), 5B188.2 [anti-nucleocapsid (N) protein, IgG2a, NT <1:100], 5B93.9 (anti-S; $\operatorname{lgA}, \mathrm{NT}:<1: 100^{28}$ ), and 5B11.5 [anti-transmembrane (M) protein, IgG2a, NT: <1:100 29 ] all provided by Dr. M. Buchmeier, Scripps Research Institute, La Jolla, CA, and irrelevant antibody [anti-keyhole limpet hemocyanin (KLH), IgG1; Sigma, St. Louis, MO]. In preliminary experiments, we determined that $5 \mu \mathrm{g}$ of mAb 5B19.2 administered intraperitoneally 4 days after infection resulted in maximum demyelination. Consequently, $5 \mu \mathrm{g}$ of $\mathrm{mAb}$ per mouse were administered except where noted below. In some experiments, adoptive transfer of splenocytes from B6 mice previously immunized intraperitoneally with JHM to infected $\mathrm{RAG} 1^{-1-}$ mice was performed as previously described. $^{7}$

\section{Virus Titration}

Virus was titered as described previously. ${ }^{27}$ Briefly, animals were sacrificed and perfused with sterile PBS. The tissues were homogenized in $6 \mathrm{ml}$ of PBS. After two cycles of freeze-thawing, supernatants were obtained by centrifugation at $800 \times g$ for 5 minutes at $4^{\circ} \mathrm{C}$. Supernatants were assayed for virus by plaque assay on HeLa cells expressing the cellular receptor for mouse hepatitis virus (HeLa-MHVR). Viral titers are represented as PFU/g of brain \pm SEM.

\section{Complement Depletion in Vivo}

To deplete complement in vivo, CVF isolated from Naja naja kaaouthia (0.5 $\mu \mathrm{g} / \mathrm{kg}$; Calbiochem, La Jolla, CA) was administered intraperitoneally in $200 \mu$ l of PBS beginning 1 day before antibody injection (3 days after infection with 
Table 1. Demyelination and Viral Titers in JHM-Infected RAG1 ${ }^{-1-}$ Mice after Antibody Transfer

\begin{tabular}{|c|c|c|c|c|c|}
\hline Antibody (isotype) & Target & Amount & Number of mice & $\%$ Demyelination (mean \pm SEM) & Viral titer $\left(\log _{10} \text { PFU/g brain }\right)^{*}$ \\
\hline Rabbit anti-JHM & JHM & $50 \mu l$ & 5 & $12.4 \pm 2.0^{\dagger}$ & $5.3 \pm 0.1^{\ddagger}$ \\
\hline Normal rabbit & None & $50 \mu l$ & 5 & $1.9 \pm 1.0$ & $5.9 \pm 0.2$ \\
\hline 5B19.2 (IgG1) & S & $5 \mu \mathrm{g}$ & 6 & $7.7 \pm 2.0^{\S}$ & $5.3 \pm 0.2$ \\
\hline 5A13.5 (IgG2a) & S & $5 \mu \mathrm{g}$ & 6 & $6.0 \pm 2.4^{\pi}$ & $5.9 \pm 0.1$ \\
\hline $5 B 93.9(\operatorname{lgA})$ & S & $5 \mu \mathrm{g}$ & 3 & $0.7 \pm 0.3$ & $6.3 \pm 0.1$ \\
\hline 5B11.5 (IgG2a) & M & $5 \mu \mathrm{g}$ & 5 & $7.7 \pm 3.4^{\|}$ & $5.7 \pm 0.2$ \\
\hline \multirow[t]{2}{*}{ 5B188.2 (lgG2a) } & $\mathrm{N}$ & $5 \mu \mathrm{g}$ & 5 & $0.9 \pm 0.7$ & $5.5 \pm 0.2$ \\
\hline & & $30 \mu \mathrm{g}$ & 9 & $2.1 \pm 1.2$ & $5.7 \pm 0.2$ \\
\hline \multirow[t]{2}{*}{ Mouse Ig (IgG1) } & $\mathrm{KLH}$ & $5 \mu \mathrm{g}$ & 9 & $0.8 \pm 0.5$ & $5.5 \pm 0.1$ \\
\hline & & $30 \mu \mathrm{g}$ & 5 & $0.9 \pm 0.6$ & $5.5 \pm 0.2$ \\
\hline PBS & None & 0 & 6 & $0.5 \pm 0.2$ & $5.4 \pm 0.1$ \\
\hline
\end{tabular}

Mice received either rabbit sera or mouse mAbs at 4 days after infection and were harvested at 14 to 16 days after infection.

*Values are shown as mean \pm SEM.

† Demyelination was significantly higher and virus titers lower in mice that received anti-JHM rabbit sera $(P<0.002$ and $P<0.05$, respectively).

§१ll Demyelination was significantly different in recipients of mAb 5B19.2 $(P<0.002)$, mAb 5A13.5 $(P<0.03)$, or mAb 5B11.5 $(P<0.02)$ when compared to recipients of anti-KLH mAb.

$\mathrm{JHM}$ ) and every 3 days thereafter until mice were harvested. Control mice received PBS alone.

\section{Luxol Fast Blue Staining and Quantification of Demyelination}

Mice were perfused with PBS. Spinal cords were fixed in $10 \%$ zinc formalin (Labesco, Solon, $\mathrm{OH}$ ) overnight and embedded in paraffin. Eight- $\mu \mathrm{m}$ longitudinal sections of entire spinal cords were prepared and stained with Luxol Fast Blue. For quantification of demyelination, spinal cord sections were photographed and digitalized using a Leitz DMB 100 microscope (Leica Microscope, Wetzler, Germany) and an Optronics digital camera (Optronics, Goleta, CA). Demyelination was quantified using ImageJ software (National Institutes of Health, Bethesda, MD) as described previously. ${ }^{4}$ Data are represented as the fraction of the total white matter of the spinal cord showing demyelination. Average demyelination per group is represented as arithmetic mean value \pm SEM.

\section{Immunohistochemical and Immunofluorescence Assays}

Eight- $\mu \mathrm{m}$ sections were prepared from zinc formalinfixed spinal cords and permeabilized with $0.1 \%$ of Triton X-100. Sections were treated with CAS Block (Zymed Laboratories, South San Francisco, CA), before incubation with primary antibody to detect macrophages/microglia [rat anti-F4/80 (Cl:A3-1; Serotec, Oxford, England), 1:200] or viral antigen [mouse anti-N (5B188.2), 1:10,000] overnight at $4^{\circ} \mathrm{C}$. After washing, sections were incubated with biotinylated goat anti-rat (F4/80) or anti-mouse (N) antibody (Jackson ImmunoResearch, West Grove, PA) diluted 1:100 for 1 hour at room temperature, followed by avidin-horseradish peroxidase. Sections were developed with 3,3'-diaminobenzidine (Sigma Chemical). For immunofluorescence assays, sections were incubated overnight with a cocktail of mouse anti-phosphoneurofilament mAbs (SMI-312; Sternberger Monoclonals, Lutherville, $\mathrm{MD}$ ) or biotinylated goat anti-rabbit IgG (Jackson Immu-
noResearch). After washing, samples were incubated with fluorescein isothiocyanate-conjugated anti-mouse IgG (Jackson ImmunoResearch) or streptavidin-Cy3 (Jackson ImmunoResearch) and examined by fluorescent microscopy.

\section{Statistics}

A two-tailed unpaired Student's $t$-test was used to analyze differences in mean values between groups.

\section{Results}

\section{RAG1 $^{-/-}$Mice Infected with JHM Developed Demyelination after Infusion of Virus-Specific Antibody}

Initially, we investigated whether polyclonal rabbit antiJHM antibody could mediate demyelination in JHM-infected RAG1 ${ }^{-1-}$ mice. JHM-infected RAG1 ${ }^{-1-}$ mice survive for 13 to 18 days after inoculation but do not develop significant levels of demyelination. ${ }^{7}$ In preliminary experiments, we determined that $50 \mu \mathrm{l}$ of a rabbit polyclonal antibody delivered intraperitoneally at 4 days after infection resulted in a significant amount of demyelination whereas administration of normal rabbit sera did not (Table 1 and Figure 1, A and D). Anti-JHM but not normal rabbit sera prolonged survival. Because mice receiving normal sera developed symptoms of severe encephalitis (hunching, lethargy, ruffled fur) by 14 to 16 days after infection, we euthanized all mice at this time. We detected $12.4 \pm 2.0 \%$ demyelination in mice receiving antiJHM sera, with $1.9 \pm 1.0 \%$ detected in recipients of normal rabbit sera $(P<0.002)$. Demyelination was accompanied by infiltration of macrophages/microglia into the white matter of the spinal cord (Figure 1, B and E). We detected viral antigen throughout the spinal cord in all mice, except in areas of demyelination (Figure 1, C and F). A similar lack of virus antigen in areas of myelin destruction was also observed in other models of JHMinduced demyelination, ${ }^{30,31}$ suggesting that demyelina- 

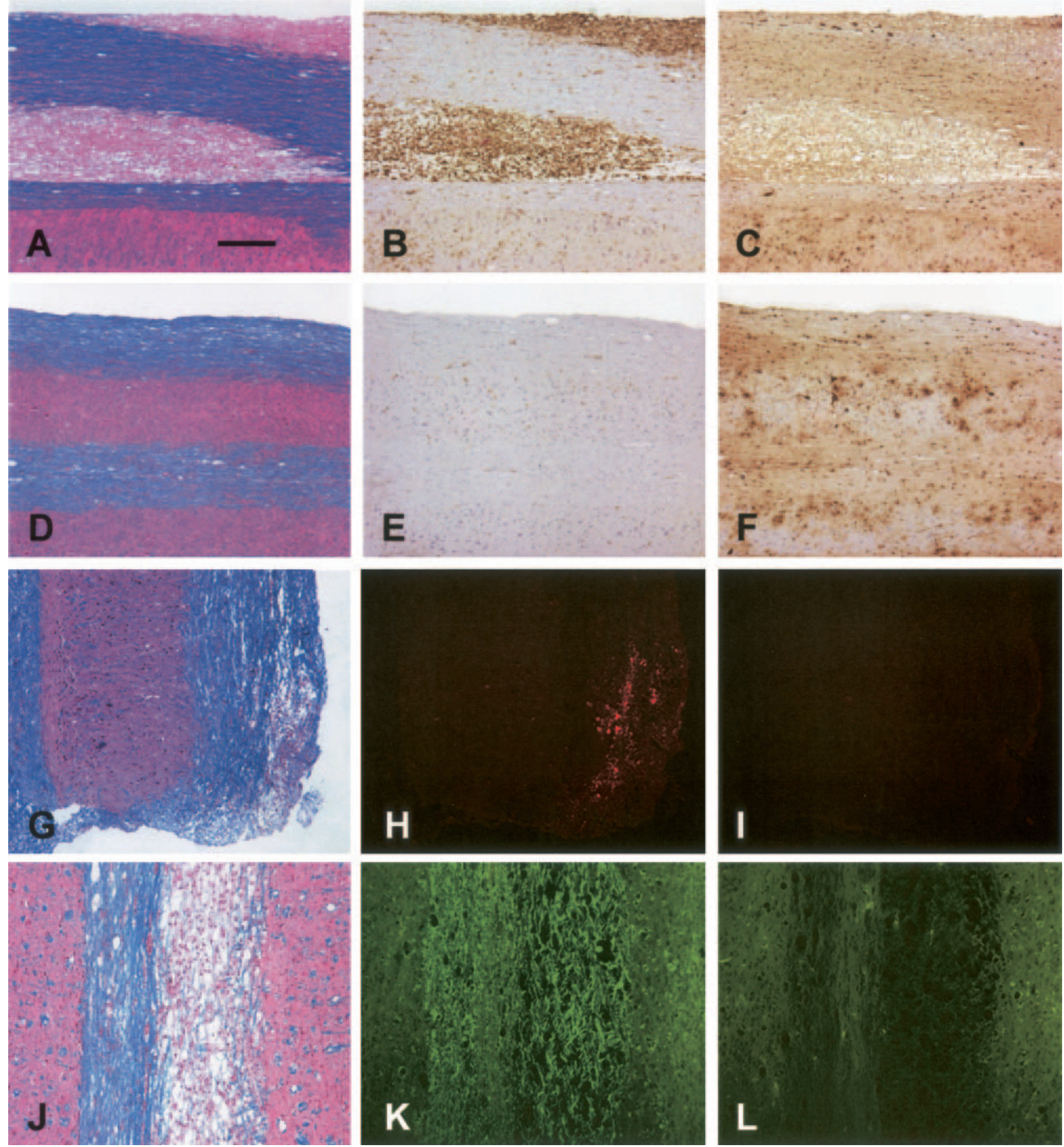

Figure 1. Detection of demyelination in anti-JHM antibody-treated mice. JHM-infected RAG1 ${ }^{-/-}$mice received the following treatments at 4 days after infection by intraperitoneal injection: $50 \mu \mathrm{l}(\mathbf{A}-\mathbf{C})$ or $500 \mu \mathrm{l}(\mathbf{G}-\mathbf{I})$ of rabbit anti-JHM sera, $50 \mu \mathrm{l}$ of rabbit normal sera $(\mathbf{D}-\mathbf{F})$, or $5 \mu \mathrm{g}$ of anti-JHM mAb $(5 \mathrm{~B} 19.2: \mathbf{J}-\mathbf{L})$. Mice were harvested at 14 to 16 days after infection and serial longitudinal sections ( $8 \mu \mathrm{m}$ thick) of spinal cord were examined for demyelination $(\mathbf{A}, \mathbf{D}, \mathbf{G}$, and $\mathbf{J})$, macrophage/microglia infiltration ( $\mathbf{B}$ and $\mathbf{E}$ ), viral antigen $(\mathbf{C}$ and $\mathbf{F})$, antibody deposition ( $\mathbf{H}$ and $\mathbf{I})$, and axons $(\mathbf{K}$ and $\mathbf{L})$ as described in Materials and Methods. Demyelination (A) and extensive macrophage/microglia infiltration into the white matter (B) were evident only in mice that received JHM-immune sera, but not in control mice (D and $\mathbf{E}$ ). However, viral antigen was uniformly distributed throughout spinal cords in both JHM-immune sera-treated (C) and control (F) mice, except in areas of demyelination $(\mathbf{C})$. Antibodies deposited in the CNS (H) were detected exclusively adjacent to areas of frank demyelination. G: An area with a moderate amount of demyelination is depicted in this figure. I: No staining was detected when an irrelevant antibody was used. Axons were preserved (K) in areas of demyelination (J). L: No staining was detected in the absence of SMI312 mAbs. Scale bars: $250 \mu \mathrm{m}(\mathbf{A}-\mathbf{I}) ; 125 \mu \mathrm{m}(\mathbf{J}-\mathbf{L})$.

tion was a consequence of virus clearance. To begin to understand the mechanism of antibody-induced demyelination, we examined spinal cord sections from antibody-treated, infected RAG $1^{-1-}$ mice for antibody dep- osition. We were unable to detect antibody in the CNS of mice that received $50 \mu \mathrm{l}$ of antibody. However, demyelination was also detected in mice that received $500 \mu$ l of rabbit anti-JHM antibody and we were able to detect 


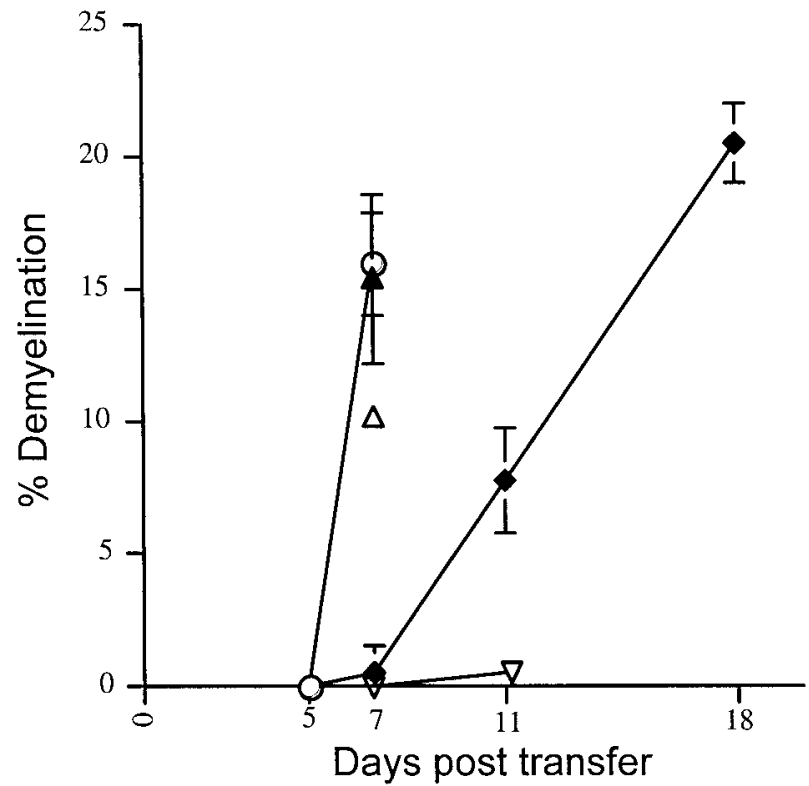

Figure 2. Kinetics of demyelination mediated by either JHM-immune splenocytes $(o, \Delta, \mathbf{\Delta})$ or JHM-specific mAb 5B19.2 $(\bullet)$ in RAG1 $1^{-/-}$mice infected with JHM. Demyelination was minimal when JHM-infected RAG1 $1^{-/-}$mice were untreated $(\nabla)$. However, rapid and robust demyelination $(15.9 \pm 1.9 \%$, $n=7 ; o$ ) was observed at 7 days after transfer of JHM-immune splenocytes, as previously described. ${ }^{7}$ Demyelination was also detected by 7 days when JHM-immune splenocytes, enriched for either CD4 $(10.2 \pm 0.6 \%, n=9 ; \Delta)$ or CD8 $(15.4 \pm 3.2 \%, n=7 ; \boldsymbol{\Delta})$ T cells were transferred to JHM-infected $\mathrm{RAG}^{-/-}$mice. ${ }^{4}$ Demyelination did not develop as rapidly after treatment with anti-S mAb but reached similar levels by 16 days after infusion $(20.5 \pm$ $1.5 \%, n=8$ ).

deposited antibody adjacent to sites of demyelination but not elsewhere in these mice (Figure 1; G to I).

If antibody were to function directly in the CNS, it would likely recognize a viral protein on the surface of infected cells. Next, we tested a panel of five anti-JHM mAbs, recognizing the $S, N$, or $M$ proteins, for their ability to mediate demyelination in infected $\mathrm{RAG}^{-1-}$ mice (Table 1). The $S$ protein is the most abundant JHM protein present on the infected cell surface and would be predicted to be the target for anti-JHM demyelinating antibody. The $\mathrm{N}$ and $\mathrm{M}$ proteins are predicted to lack surface expression. However, previous reports suggested that $\mathrm{N}$ and M-specific antibody epitopes are expressed on the cell surface. ${ }^{32,33}$ Administration of mAb 5B19.2 (anti-S) protected infected RAG1 ${ }^{-1-}$ mice partially from acute encephalitis and prolonged survival from 14 to 16 days after infection in the absence of anti-JHM antibody to 18 to 20 days after infection. mAb 5B19.2-treated mice exhibited clinical signs of demyelination including wobbly gait and limb paresis starting at 12 to 14 days after infection and showed histological evidence of demyelination $[7.7 \pm 2.0 \%$ at 15 days after infection (Figures $1 \mathrm{~J}$ and 2 ) and $20.5 \pm 1.5 \%$ at 18 to 20 days after infection]. We determined whether the amount of mAb 19.2 present in the serum of $\mathrm{RAG}^{-1-}$ mice was similar to levels of anti-JHM antibody detected in JHM-infected B6 mice undergoing demyelination. Serum NTs, which primarily measure the anti-S antibody response, were similar between the two groups: $1: 32$ (range, $1: 19$ to $1: 45 ; n=2$ ) at
2 days after $\mathrm{mAb} 19.2$ transfer versus 1:86.2 $\pm 42.7(n=$ 4) at 21 days after infection in JHM-infected B6 mice.

Mice that received irrelevant antibody (anti-KLH) or PBS developed only insignificant amounts of demyelination (Table 1). By comparison, JHM-infected RAG1 ${ }^{-1-}$ recipients of JHM-immune splenocytes exhibited similar amounts of demyelination, although the kinetics of myelin destruction was more rapid, with demyelination detected by 7 to 8 days after infection (Figure 2). ${ }^{4,7}$ Demyelination in mAb 5B19.2-treated mice did not reflect differences in virus clearance because similar amounts of virus were detected in recipients of anti-JHM mAb, PBS, or irrelevant antibody (Table 1). This inability to detect a difference in virus titer, in the presence of prolonged survival, may reflect a transient reduction in virus titer at early times after infection.

As expected, histological examination of sections from mAb 5B19.2-treated mice revealed the presence of activated macrophages/microglia adjacent to demyelinated areas (data not shown). To quantify the number of macrophages/microglia after antibody transfer, we counted the number of macrophages/microglia in the gray and white matter of mid-sagittal sections of spinal cords from three mice that received either mAb 5B19.2 or irrelevant antibody. In these experiments, all of the $\mathrm{F} 4 / 80^{+}$cells in $1.25-\mathrm{mm}$-wide cross-sections at 10 levels within spinal cords were counted. The number of macrophages/microglia present per cross-sectional area increased threefold after infusion of anti-JHM antibody compared to those that received control antibody $(66.7 \pm 3.7$ versus $23.3 \pm$ $2.9, P<0.001)$. These additional infiltrating $\mathrm{F} 4 / 80^{+}$cells were localized entirely to the white matter. In other models, JHM-induced demyelination was primary and not secondary to axonal damage. ${ }^{30}$ Similarly, demyelination induced by anti-JHM antibody was primary, because intact axons were detected traversing areas of demyelination (Figure 1, $\mathrm{K}$ and $\mathrm{L}$ ).

To examine whether the induction of demyelination after antibody transfer was unique to mAb 5B19.2, four additional mAbs were analyzed: mAb 5A13.5 (anti-S), mAb 5B93.9 (anti-S), mAb 5B11.5 (anti-M), and mAb 5B188.2 (anti-N) (Table 1). None of these antibodies, regardless of their specificity, exhibited a protective effect because all mice were moribund by 14 to 16 days after infection, when $5 \mu \mathrm{g}$ were administered. This result was not expected, because mAb 5A13.5 has a high neutralizing antibody titer (1:6230 PRD/mg) and has been reported to protect $B 6$ mice from encephalitis. ${ }^{29}$ We found, however, that mAb 5A13.5 was inefficient compared to mAb 5B19.2 at protecting B6 mice from acute encephalitis after inoculation with neurovirulent JHM (data not shown). Mice that received $5 \mu \mathrm{g}$ of mAb 5A13.5 showed clinical signs of demyelination, including difficulty righting and hindlimb paresis, with demyelination detected on histological examination $(6.0 \pm 2.4 \%)$. This was within the range of demyelination observed in mice treated with mAb 5B19.2 and harvested at the same time after infection. Increasing the amount of mAb 5A13.5 administered from 5 to $30 \mu \mathrm{g}$ prolonged mouse survival up to 20 days after infection and resulted in clinical outcomes and amounts of demyelination (22.5 $\pm 5.6 \%$, 
Table 2. Role of FCR and Complement in Antibody-Mediated Demyelination

\begin{tabular}{|c|c|c|c|c|}
\hline Animals & Number of mice & Days after infection & $\%$ Demyelination (mean \pm SEM) & Viral titers $\left(\log _{10} P F U / g \text { brain }\right)^{*}$ \\
\hline $\mathrm{FCR} \gamma^{+/-} \mathrm{RAG}^{-1-}$ & 6 & 17 & $9.1 \pm 1.4^{\dagger}$ & $5.9 \pm 0.1$ \\
\hline $\mathrm{FCR} \gamma^{-1-} \mathrm{RAG}^{-1-}$ & 9 & 17 & $1.2 \pm 0.4^{\dagger}$ & $6.0 \pm 0.1$ \\
\hline $\mathrm{RAG}^{-1-}+$ CVF & 6 & $18-20$ & $5.8 \pm 1.9^{\ddagger}$ & $6.0 \pm 0.1^{\S}$ \\
\hline $\mathrm{RAG}_{1}{ }^{-1-}+\mathrm{PBS}$ & 5 & $18-20$ & $24.1 \pm 4.9^{\ddagger}$ & $5.5 \pm 0.2^{\S}$ \\
\hline
\end{tabular}

Mice were treated with $5 \mu \mathrm{g}$ of anti-MHV S mAb (mAb 5B19.2) at 4 days after infection.

*Values are shown as mean \pm SEM.

${ }^{+} \mathrm{FCR} \gamma^{+/-} \mathrm{RAG}^{-1-}$ mice had significantly more demyelination than $\mathrm{FCR} \gamma^{-1-} \mathrm{RAG} 1^{-1-}$ mice $(P<0.0001)$.

${ }^{\ddagger}$ CVF-treated mice had significantly less demyelination and significantly higher virus titers than control mice $(P<0.02$ and $P<0.01$, respectively).

$n=8$ ) indistinguishable from those of mice treated with mAb 5B19.2 and also harvested at 18 to 20 days after infection.

Another anti-S antibody, mAb 5B93.9, which was not neutralizing in vitro, ${ }^{28}$ did not mediate demyelination. The single anti-M antibody that we analyzed also mediated demyelination in infected RAG1 $1^{-/-}$mice (Table 1). Although $\mathrm{M}$ protein is primarily an internal viral protein, at least one anti-M mAb has been shown to neutralize JHM infectivity in vitro and to protect mice from acute encephalitis, ${ }^{33}$ consistent with surface expression. At present, it is not known whether the epitope recognized by $\mathrm{mAb}$ $5 \mathrm{~B} 11.5$ is exposed on the infected cell surface. Transfer of $5 \mu \mathrm{g}$ of antibodies specific for either $\mathrm{N}$ or $\mathrm{KLH}$ to infected RAG1 ${ }^{-1-}$ mice did not prolong survival or result in increased demyelination when compared to mice that received no antibody (Table 1$)$. Thirty $\mu \mathrm{g}$ of anti-N antibody treatment, while not prolonging survival, resulted in demyelination in two of nine mice; this may reflect antibody access to nucleocapsid protein in some animals.

\section{JHM-Infected RAG1 ${ }^{-1-}$ Mice Deficient in Activating FcyRs Exhibited a Reduction in the Frequency and Amount of Demyelination}

To begin to delineate the mechanism(s) of antibodymediated demyelination, we first determined the role of activating $\mathrm{FCRs}_{\mathrm{C}}\left(\mathrm{Fc}_{\mathrm{c}} \boldsymbol{\mathrm { RI }}\right.$ and $\left.\mathrm{F}_{\mathrm{C}} \gamma \mathrm{RIII}\right)$ in this process. For this purpose, we generated $\mathrm{FCR} \gamma^{-1-} \mathrm{RAG}_{1}^{-1-}$ mice. These mice are deficient in $\mathrm{F}_{\mathrm{c}} \gamma \mathrm{RI}$ and $\mathrm{F}_{\mathrm{c}} \gamma \mathrm{R}$ III expression, in addition to lacking $\mathrm{T}$ and $\mathrm{B}$ cells, and are therefore useful for investigating the role of FcR-dependent pathways in antibody-induced demyelination. FcR $\gamma^{-l-}$ mice express $\sim 20 \%$ as much Fc $\gamma \mathrm{Rl}$ as wild-type mice, but no FcyRIII and exhibit impaired phagocytic function. ${ }^{34}$ In preliminary experiments, we observed that $\mathrm{FCR} \gamma^{+/-} \mathrm{RAG}^{-1-}$ mice were slightly more resistant to JHM infection than RAG $1^{-/-}$mice, surviving 1 to 2 days longer, although no demyelination developed in any of these mice. This difference may reflect a difference in genetic lineage because $\mathrm{FCR} \gamma^{-1-}$ mice were obtained on a B6x129 background. Consequently, heterozygous littermates were infected to control for potential genetic differences. FcR $\gamma^{-1-} \mathrm{RAG}^{-1-}$ mice were more susceptible to JHM than were their FCR $\gamma^{+/-} \mathrm{RAG}^{-1-}$ littermates, with death occurring by $14.7 \pm 1.5$ days versus $17.0 \pm$ 2.7 days after infection. The basis for this difference is not understood because no antibody is present in these an- imals. This enhanced susceptibility to JHM was even more evident after treatment with mAb 5B19.2, with FCR $\gamma^{-1-} \mathrm{RAG}^{-1-}$ mice moribund by 17 days after infection whereas $\mathrm{JHM}$-infected FCR $\gamma^{+/-} \mathrm{RAG}^{-1-}$ mice survived for greater than 20 days after infection. All mice, therefore, were examined for viral load and demyelination in the CNS at 17 days after infection (Table 2). mAb 5B19.2-treated FCR $\gamma^{-1-} \mathrm{RAG}^{-1-}$ mice developed clinical signs of acute encephalitis such as hunching, lethargy, and ruffled fur by this time. In contrast, mAb 5B19.2treated $\mathrm{FCR} \gamma^{+/-} \mathrm{RAG}^{-1-}$ mice from the same litters exhibited primarily hindlimb weakness. Consistent with these clinical observations, demyelination in $\mathrm{FcR} \gamma^{-1-}$ $\mathrm{RAG}^{-1-}$ mice was significantly reduced compared to controls $(9.1 \pm 1.4 \%$ versus $1.2 \pm 0.4 \%, P<0.0001)$ (Table 2). These results were not explained by differences in virus titer because similar amounts of infectious virus were present in both $\mathrm{FCR} \gamma^{+/-} \mathrm{RAG}_{1}^{-1-}$ and $\mathrm{FCR} \gamma^{-1-}$ $\mathrm{RAG}^{-1-}$ mice (Table 2).

\section{Antibody-Mediated Demyelination Was Also Dependent on an Intact Complement Pathway}

As described above, complement is a key component in rodent models of antibody-induced EAE. Additionally, recent studies showed that antibody-mediated autoimmune disease was dependent on both intact complement and FcR pathways for maximal disease expression. ${ }^{35,36}$ Consequently, we next evaluated the role of complement in anti-JHM antibody-induced demyelination, using CVF, a homolog of $\mathrm{C} 3 \mathrm{~b}$, to deplete complement. Mice were treated with CVF at dosages and frequency shown previously to result in complement depletion $(0.5 \mu \mathrm{g} / \mathrm{kg}$ beginning 1 day before antibody injection and every 3 days thereafter). ${ }^{19,37}$ CVF treatment in the presence of $\mathrm{mAb}$ 5B19.2 did not alter survival, with mice becoming moribund at 18 to 20 days after infection, similar to mice that received only antibody. However, mice treated with CVF showed clinical signs of encephalitis including hunching lethargy, and ruffled fur, but few signs of demyelination (difficulty righting, hindlimb paresis) when compared to control mice. CVF treatment resulted in a slight increase in virus titer in the CNS $\left(5.5 \pm 0.2 \log _{10} \mathrm{PFU} / \mathrm{g}\right.$ brain versus $6.0 \pm 0.1 \log _{10}$ PFU/g brain, $\left.P<0.02\right)$. Quantification of demyelination revealed a $76 \%$ reduction after CVF treatment compared to PBS-treated animals (24.1 \pm $4.9 \%$ versus $5.8 \pm 1.9 \%, P<0.01$ ) (Table 2 ). The amount of demyelination was greater in these experiments than in 
those described above because mice were sampled 3 to 6 days later after infection (Figure 2).

\section{Discussion}

Previously, we and others showed that infusion of T cells into JHM-infected $\mathrm{RAG}^{-1-}$ or severe combined immunodeficiency mice resulted in demyelination. ${ }^{7,38}$ In this study, we extend these results to show that anti-JHM antibodies, in the absence of $\mathrm{T}$ cells, are also able to mediate demyelination in the same experimental system. Infusion of anti-KLH antibody or normal rabbit sera did not cause demyelination, showing that nonspecific binding to infected cells or to FcR on macrophages was inadequate to initiate this process. Furthermore, only some anti-virus antibodies were able to mediate demyelination. We cannot draw firm conclusions about the characteristics of anti-virus antibodies that allow them to mediate demyelination because only a limited number were examined in our study. It is likely that the viral epitopes recognized by demyelinating antibodies must be expressed on the cell surface although this has not been formally proven for mAb 5B11.5, the anti-M mAb that was able to induce demyelination. One anti-S antibody, mAb 5B93.9, did not mediate demyelination. This $\mathrm{mAb}$ may not be demyelinating because it is an IgA antibody, or because the epitope that it recognizes is not fully accessible on the native $S$ glycoprotein.

Antibody-induced demyelination did not occur only after infection with the neuroattenuated $\mathrm{J} 2.2$ variant of $\mathrm{JHM}$ used in this study. Robust demyelination occurred in anti-JHM antibody-treated RAG $1^{-1-}$ mice intranasally infected with $5 \times 10^{4} \mathrm{PFU}$ of the parental neurovirulent JHM strain. In this instance, a larger amount of antibody (10 $\mu \mathrm{g}$ of mAb 5B19.2) was required to enhance survival, but demyelination $(32.3 \pm 5.2 \%, n=7)$ was observed at 13 to 20 days after infection. In addition, Matthews and colleagues $^{39}$ showed that the A59 strain of mouse hepatitis virus also induced substantial amounts of demyelination when RAG $1^{-1-}$ mice were infected in the presence of virus-specific hyperimmune serum.

Antibodies capable of initiating myelin destruction may function by one or more mechanisms. Virus-specific antibody may directly interact with infected cells in the CNS, thereby resulting in the expression of chemoattractants for macrophages/microglia. Consistent with this possibility, anti-JHM antibody was detected at sites of demyelination (Figure $1 \mathrm{H}$ ). CCL2/monocyte chemotactic protein- 1 and CCL3/macrophage inflammatory protein- $1 \alpha$ have been identified as crucial for macrophage/microglia infiltration in $\mathrm{EAE}^{40-42}$ and CCL2 and CCL5/RANTES were implicated in macrophage infiltration into the $\mathrm{JHM}$ infected CNS. ${ }^{43,44}$ However, these chemokines are expressed at high levels in the JHM-infected RAG1 ${ }^{-1-}$ $\mathrm{CNS}^{8}$ and we have been unable to detect differences in expression of these chemokines after T-cell transfer that correlate with extent of demyelination. ${ }^{45,46}$ Thus, if these chemokines are important in antibody-mediated demyelination, it is likely that there will be localized differences in expression, rather than substantial changes in total pro- duction in the CNS. Alternatively, antibody may bind to circulating virus antigen and the resulting immune complexes may activate macrophages in the periphery. Because the milieu of the $\mathrm{JHM}$-infected RAG1 ${ }^{-1-}$ CNS is proinflammatory, ${ }^{8}$ this peripheral activation may be all that is required for demyelination to occur. Precedent for this comes from EAE studies, because peripheral activation of macrophages is critical in the development of disease. ${ }^{47}$

Both complement and Fc $\gamma$ R-dependent pathways were implicated in antibody-mediated demyelination in JHM-infected RAG $1^{-1-}$ mice, at least when mAb 5B19.2 was infused. mAb 5B19.2 is an IgG1 antibody, a subclass that activates complement poorly through the classical pathway. It is conceivable that the relative contribution of each pathway to demyelination would change if an antibody that was more effective in fixing complement were used. The role of complement in autoimmune disease, including EAE, remains controversial, partly because the effects of complement are pleiotropic. Some studies suggested that early components of the complement pathway were most critical. C3b and C4b may function as an opsonin for myelin, thereby enhancing phagocytosis by macrophages. ${ }^{48,49} \mathrm{C} 3 \mathrm{a}$ and $\mathrm{C} 5 \mathrm{a}$ are chemoattractants for monocytes/macrophages ${ }^{25}$ and thereby may directly contribute to the influx of these cells into the white matter. Both of these complement products are anaphylatoxins and have multiple proinflammatory effects on macrophages, including enhancing differentiation and cytokine release. ${ }^{50}$ Additionally, C5a, via binding to $\mathrm{C} 5 \mathrm{aR}$, enhances the expression of activating FcyRs and diminishes that of Fc $\gamma R$ Illb, an inhibitory $\mathrm{Fc}_{\mathrm{C}} \mathrm{R}$. $^{50}$ This property of C5a may contribute to the requirement for both complement- and FcR-dependent pathways for maximal demyelination in JHM-infected mice. Other studies, using rodents deficient in C6 expression, suggest that formation of the MAC is critical for demyelination in antibody-induced EAE. Demyelination and inflammatory cell infiltration were greatly reduced in $\mathrm{C6}^{-1-}$ rats with $\mathrm{EAE}^{22,23} \mathrm{MAC}$, by directly damaging infected oligodendrocytes, may contribute to an inflammatory cascade, resulting in macrophage infiltration and demyelination in JHM-infected mice. MAC, in sublytic amounts, may also contribute to inflammation by activating target cells. ${ }^{51}$

Fc $\gamma$ Rs were also critical for antibody-induced demyelination in JHM-infected RAG1 ${ }^{-1-}$ mice. Although Fc $\gamma R s$ may be involved in antigen presentation, ${ }^{52}$ this function is unlikely to be important in RAG1 ${ }^{-1-}$ mice. More likely, macrophages/microglia are activated via the immunoreceptor tyrosine-based activation motif present on the $\gamma$ chain of activating Fc $\gamma$ Rs. Activation via the Fc $\gamma R$ may not only enhance recruitment of macrophages/microglia to the infected white matter, but also may be involved in release of cytokines including tumor necrosis factor- $\alpha$ and interleukin-1 and the release of substances such as oxygen radicals that may directly damage myelin. ${ }^{53}$

Requirements for both complement- and Fc $\gamma$ R-dependent pathways have been demonstrated in other antibody-mediated pathological conditions, including immune complex-mediated skin and lung disease ${ }^{36,50}$ and 
inflammatory arthritis. ${ }^{35}$ Collectively, these studies suggest that antibody binding to infected oligodendrocytes leads to generation of $\mathrm{C} 3 \mathrm{a}$ and $\mathrm{C} 5 \mathrm{a}$ and the formation of MAC as well as the activation of macrophages/microglia via FcR-dependent pathways. This results in increased migration of these cells into the white matter of the spinal cord with subsequent destruction of infected oligodendrocytes and myelin. Our results emphasize the multifactorial and complex nature of the demyelinating process. Although $\alpha \beta$ T cells are generally responsible for the bulk of immune-mediated myelin damage in most experimental models, either $\gamma \delta \mathrm{T}$ cells $^{31}$ or antibody directed against an antigen present in the CNS (JHM in our experiments) can also mediate demyelination. In patients with MS, T cells are also believed to be critical for the development of inflammation. However, IgG and complement deposition are detected in demyelinating lesions in MS lesions, consistent with a role in myelin destruction, and have also been implicated in the initial stages of the demyelinating process. ${ }^{16,54}$ Our results show, that under the appropriate circumstances, antibodies in the absence of $T$ cells can cause demyelination.

\section{Acknowledgments}

We thank Dr. John Harty and Ajai Dandekar for critical review of the manuscript.

\section{References}

1. Hemmer B, Archelos JJ, Hartung HP: New concepts in the immunopathogenesis of multiple sclerosis. Nat Rev Neurosci 2002, 3:291301

2. Noseworthy $\mathrm{JH}$ : Progress in determining the causes and treatment of multiple sclerosis. Nature 1999, 399:A40-A47

3. Steinman L: Assessment of animal models for MS and demyelinating disease in the design of rational therapy. Neuron 1999, 24:511-514

4. Wu GF, Dandekar AA, Pewe L, Perlman S: CD4 and CD8 T cells have redundant but not identical roles in virus-induced demyelination. J Immunol 2000, 165:2278-2286

5. Wang F, Stohlman SA, Fleming JO: Demyelination induced by murine hepatitis virus JHM strain (MHV-4) is immunologically mediated. J Neuroimmunol 1990, 30:31-41

6. Houtman JJ, Fleming JO: Dissociation of demyelination and viral clearance in congenitally immunodeficient mice infected with murine coronavirus JHM. J Neurovirol 1996, 2:101-110

7. Wu GF, Perlman S: Macrophage infiltration, but not apoptosis, is correlated with immune-mediated demyelination following murine infection with a neurotropic coronavirus. J Virol 1999, 73:8771-8780

8. Haring JS, Pewe LL, Perlman S: Bystander CD8 T cell-mediated demyelination after viral infection of the central nervous system. J Immunol 2002, 169:1550-1555

9. Archelos JJ, Storch MK, Hartung HP: The role of B cells and autoantibodies in multiple sclerosis. Ann Neurol 2000, 47:694-706

10. Owens GP, Ritchie AM, Burgoon MP, Williamson RA, Corboy JR, Gilden DH: Single-cell repertoire analysis demonstrates that clonal expansion is a prominent feature of the $\mathrm{B}$ cell response in multiple sclerosis cerebrospinal fluid. J Immunol 2003, 171:2725-2733

11. Levin LI, Munger KL, Rubertone MV, Peck CA, Lennette ET, Spiegelman D, Ascherio A: Multiple sclerosis and Epstein-Barr virus. JAMA 2003, 289:1533-1536

12. Burgoon MP, Hammack BN, Owens GP, Maybach AL, Eikelenboom MJ, Gilden DH: Oligoclonal immunoglobulins in cerebrospinal fluid during varicella zoster virus (VZV) vasculopathy are directed against VZV. Ann Neurol 2003, 54:459-463

13. Raine CS, Cannella B, Hauser SL, Genain CP: Demyelination in primate autoimmune encephalomyelitis and acute multiple sclerosis lesions: a case for antigen-specific antibody mediation. Ann Neurol 1999, 46:144-160

14. Noseworthy JH, Lucchinetti C, Rodriguez M, Weinshenker BG: Multiple sclerosis. N Engl J Med 2000, 343:938-952

15. Berger T, Rubner P, Schautzer F, Egg R, Ulmer $H$, Mayringer I, Dilitz E, Deisenhammer F, Reindl M: Antimyelin antibodies as a predictor of clinically definite multiple sclerosis after a first demyelinating event. N Engl J Med 2003, 349:139-145

16. Lucchinetti C, Bruck W, Parisi J, Scheithauer B, Rodriguez M, Lassmann $\mathrm{H}$ : Heterogeneity of multiple sclerosis lesions: implications for the pathogenesis of demyelination. Ann Neurol 2000, 47:707-717

17. Wekerle H: Remembering MOG: autoantibody mediated demyelination in multiple sclerosis? Nat Med 1999, 5:153-154

18. Genain CP, Cannella B, Hauser SL, Raine CS: Identification of autoantibodies associated with myelin damage in multiple sclerosis. Nat Med 1999, 5:170-175

19. Linington C, Morgan BP, Scolding NJ, Wilkins P, Piddlesden S, Compston DA: The role of complement in the pathogenesis of experimental allergic encephalomyelitis. Brain 1989, 112:895-911

20. Nataf S, Carroll SL, Wetsel RA, Szalai AJ, Barnum SR: Attenuation of experimental autoimmune demyelination in complement-deficient mice. J Immunol 2000, 165:5867-5873

21. Calida DM, Constantinescu C, Purev E, Zhang GX, Ventura ES, Lavi E, Rostami A: Cutting edge: C3, a key component of complement activation, is not required for the development of myelin oligodendrocyte glycoprotein peptide-induced experimental autoimmune encephalomyelitis in mice. J Immunol 2001, 166:723-726

22. Tran GT, Hodgkinson SJ, Carter N, Killingsworth M, Spicer ST, Hall BM: Attenuation of experimental allergic encephalomyelitis in complement component 6-deficient rats is associated with reduced complement C9 deposition, P-selectin expression, and cellular infiltrate in spinal cords. J Immunol 2002, 168:4293-4300

23. Mead RJ, Singhrao SK, Neal JW, Lassmann H, Morgan BP: The membrane attack complex of complement causes severe demyelination associated with acute axonal injury. J Immunol 2002, 168:458465

24. Abdul-Majid KB, Stefferl A, Bourquin C, Lassmann $H$, Linington $C$ Olsson T, Kleinau S, Harris RA: FC receptors are critical for autoimmune inflammatory damage to the central nervous system in experimental autoimmune encephalomyelitis. Scand J Immunol 2002, 55: 70-81

25. Song WC, Sarrias MR, Lambris JD: Complement and innate immunity Immunopharmacology 2000, 49:187-198

26. Kim AH, Dimitriou ID, Holland MC, Mastellos D, Mueller YM, Altman JD, Lambris JD, Katsikis PD: Complement C5a receptor is essential for the optimal generation of antiviral CD8+ T cell responses. J Immunol 2004, 173:2524-2529

27. Perlman S, Schelper R, Bolger E, Ries D: Late onset, symptomatic demyelinating encephalomyelitis in mice infected with MHV-JHM in the presence of maternal antibody. Microbiol Pathog 1987, 2:185194

28. Collins AR, Knobler RL, Powell H, Buchmeier MJ: Monoclonal antibodies to murine hepatitis virus-4 (strain JHM) define the viral glycoprotein responsible for attachment and cell-cell fusion. Virology 1982 , 119:358-371

29. Buchmeier MJ, Lewicki HA, Talbot PJ, Knobler RL: Murine hepatitis virus-4 (strain JHM)-induced neurologic disease is modulated in vivo by monoclonal antibody. Virology 1984, 132:261-270

30. Stohlman SA, Hinton DR: Viral induced demyelination. Brain Pathol 2001, 11:92-106

31. Dandekar AA, Perlman S: Virus-induced demyelination in nude mice is mediated by gamma delta T cells. Am J Pathol 2002, 161:12551263

32. Kyuwa S, Cohen M, Nelson G, Tahara SM, Stohlman SA: Modulation of cellular macromolecular synthesis by coronavirus: implication for pathogenesis. J Virol 1994, 68:6815-6819

33. Fleming JO, Shubin RA, Sussman MA, Casteel N, Stohlman SA: Monoclonal antibodies to the matrix (E1) glycoprotein of mouse hepatitis virus protect mice from encephalitis. Virology 1989, 168:162167

34. Barnes N, Gavin AL, Tan PS, Mottram P, Koentgen F, Hogarth PM: FcgammaRl-deficient mice show multiple alterations to inflammatory and immune responses. Immunity 2002, 16:379-389 
35. Ji H, Ohmura K, Mahmood U, Lee DM, Hofhuis FM, Boackle SA, Takahashi K, Holers VM, Walport M, Gerard C, Ezekowitz A, Carroll MC, Brenner M, Weissleder R, Verbeek JS, Duchatelle V, Degott C, Benoist C, Mathis D: Arthritis critically dependent on innate immune system players. Immunity 2002, 16:157-168

36. Baumann U, Kohl J, Tschernig T, Schwerter-Strumpf K, Verbeek JS, Schmidt RE, Gessner JE: A codominant role of Fc gamma RI/III and C5aR in the reverse Arthus reaction. J Immunol 2000, 164:1065-1070

37. Vriesendorp FJ, Flynn RE, Malone MR, Pappolla MA: Systemic complement depletion reduces inflammation and demyelination in adoptive transfer experimental allergic neuritis. Acta Neuropathol (Berl) 1998, 95:297-301

38. Bergmann CC, Parra B, Hinton DR, Ramakrishna C, Dowdell KC, Stohlman SA: Perforin and gamma interferon-mediated control of coronavirus central nervous system infection by CD8 T cells in the absence of CD4 T cells. J Virol 2004, 78:1739-1750

39. Matthews AE, Lavi E, Weiss SR, Paterson Y: Neither B cells nor T cells are required for $\mathrm{CNS}$ demyelination in mice persistently infected with MHV-A59. J Neurovirol 2002, 8:257-264

40. Mahad DJ, Ransohoff RM: The role of MCP-1 (CCL2) and CCR2 in multiple sclerosis and experimental autoimmune encephalomyelitis (EAE). Semin Immunol 2003, 15:23-32

41. Huang DR, Wang J, Kivisakk P, Rollins BJ, Ransohoff RM: Absence of monocyte chemoattractant protein 1 in mice leads to decreased local macrophage recruitment and antigen-specific $T$ helper cell type 1 immune response in experimental autoimmune encephalomyelitis. $J$ Exp Med 2001, 193:713-726

42. Youssef S, Wildbaum G, Maor G, Lanir N, Gour-Lavie A, Grabie N, Karin N: Long-lasting protective immunity to experimental autoimmune encephalomyelitis following vaccination with naked DNA encoding C-C chemokines. J Immunol 1998, 161:3870-3879

43. Glass WG, Hickey MJ, Hardison JL, Liu MT, Manning JE, Lane TE: Antibody targeting of the CC chemokine ligand 5 results in diminished leukocyte infiltration into the central nervous system and reduced neurologic disease in a viral model of multiple sclerosis. J Immunol 2004, 172:4018-4025
44. Chen BP, Kuziel WA, Lane TE: Lack of CCR2 results in increased mortality and impaired leukocyte activation and trafficking following infection of the central nervous system with a neurotropic coronavirus. J Immunol 2001, 167:4585-4592

45. Pewe L, Haring J, Perlman S: CD4 T-cell-mediated demyelination is increased in the absence of gamma interferon in mice infected with mouse hepatitis virus. J Virol 2002, 76:7329-7333

46. Pewe LL, Perlman S: CD8 T cell-mediated demyelination is IFN- $\gamma$ dependent in mice infected with a neurotropic coronavirus. J Immunol 2002, 168:1547-1551

47. Tran EH, Hoesktra K, van Rooijen N, Dijkstra CD, Owens T: Immune invasion of the central nervous system parenchyma and experimental allergic encephalomyelitis, but not leukocyte extravasation from blood, are prevented in macrophage-depleted mice. J Immunol 1998, 161:3767-3775

48. Smith ME: Phagocytosis of myelin in demyelinative disease: a review. Neurochem Res 1999, 24:261-268

49. van der Laan LJ, Ruuls SR, Weber KS, Lodder IJ, Dopp EA, Dijkstra $\mathrm{CD}$ : Macrophage phagocytosis of myelin in vitro determined by flow cytometry: phagocytosis is mediated by $\mathrm{CR} 3$ and induces production of tumor necrosis factor-alpha and nitric oxide. J Neuroimmunol 1996, $70: 145-152$

50. Shushakova N, Skokowa J, Schulman J, Baumann U, Zwirner J, Schmidt RE, Gessner JE: C5a anaphylatoxin is a major regulator of activating versus inhibitory FcgammaRs in immune complex-induced lung disease. J Clin Invest 2002, 110:1823-1830

51. Speth C, Dierich MP, Gasque P: Neuroinvasion by pathogens: a key role of the complement system. Mol Immunol 2002, 38:669-679

52. Ravetch JV, Bolland S: IgG Fc receptors. Annu Rev Immunol 2001 19:275-290

53. Takai T: Roles of Fc receptors in autoimmunity. Nat Rev Immunol 2002, 2:580-592

54. Gay FW, Drye TJ, Dick GW, Esiri MM: The application of multifactoria cluster analysis in the staging of plaques in early multiple sclerosis. Identification and characterization of the primary demyelinating lesion. Brain 1997, 120:1461-1483 